\title{
Cytotoxicity Effects of Mouse IgG Produced against Three Nanoliposomal Human DR5 Receptor Epitopes on Breast Cancer Cells
}

\author{
Shaghayegh Amirijavid', Maliheh Entezari', Abolfazl Movafagh ${ }^{2}$, Mehrdad \\ Hashemi $^{1 *}$, Alireza Mosavi-Jarahi ${ }^{3}$, Hossein Dehghani ${ }^{4 *}$
}

\begin{abstract}
Cancer causes cells to avoid death while being the second cause of death in the world itself. Damaged cells in the absence of apoptosis will increasingly amplify their inefficient genome. Of the two main apoptosis inducing pathways in cells, the first has p53 protein as the main initiating factor in the cascade. According to research results this protein s mutated in $50 \%$ of cancers and sointerest has cooncentrated on the second pathway that features death receptors. Among these receptors TRAIL1/DR5 is especially expressed in cancer cells. So targeting such receptors can initiate the apoptotic cascade in cells. Interestingly by substitution of activating ligands with antibodies as agonists, we could efficiently turn on the apoptosis pathway. First of all, three small peptides from the DR5 protein extracellular domain were synthesized and injected with two different kind of adjuvants (Fround and liposomal encapsulation) separately into mice at 15 day intervals. As a result, liposomal peptides induced the immune system more efficient than Frounds adjuvant and at the end point the antibodies which were obtained from liposomal peptide injection induced much more effective death. Liposomal formol could be used as an adjuvant in immunization utilizing small peptides. They carry, protect and deliver peptides very efficiently. In addition, small peptides of a certain size from the extracellular domain of DR5 proteins not only can induce immune system but also produce antibodies playing a remarkable anti-cancer roles against breast cancer cells (MCF-7).
\end{abstract}

Keywords: Cancer - apoptosis - DR5, trail - liposome - adjuvant

Asian Pac J Cancer Prev, 17, Cancer Control in Western Asia Special Issue, 257-261

\section{Introduction}

Cancer is a genetic disease in which genomic mutations cause deregulation of cell critical processes including growth and death, At finally, it leads to the uncontrolled cell growth without death and cancerous cells birth (Bellail et al., 2009). One of the most interested pathways of cancer treatment is apoptosis induction. Apoptosis is the best way of evoking death especially in targeted cells with minimum side effects (Reed, 2006). Apoptosis is a genetically programmed biochemical process that removes unwanted cells and maintains tissue homeostasis under physiological and pathological conditions. practically, there are two pathways that control the initiation of apoptosis: the death receptor-mediated extrinsic pathway and the mitochondria-involved intrinsic pathway (Benedict et al., 2003). TNF receptor superfamilly regulates the apoptosis in the first pathway. The extracellular domain of TNF receptors has cystein rich domains (CRDs) which conclude six cystein repeat and three or four disulfide bonds consequently (Bodmer et al., 2002; Cha et al., 2000). Tumor necrosis factor related apoptosis- inducing ligand (TRAIL) or Apo2 ligand (TRAIL/Apo2) is a member of TNF family and discovered by Wiley et al., in 1995, searching TNF family proteins homologouses in EST database (Wiley et al., 1995; Mahalingam et al., 2009). This protein binds to the DR4 (Pan et al., 1997; Schneider et al., 1997 ) and DR5 (Chaudhary et al., 1997; Walczak et al., 1997; Wu et al., 1997) receptors and activates apoptotic pathways selectively in cancerous cells (Ashkenazi, 2002). Specific killing activity of TRAIL on various tumor cells has brought about great interests to this target or its antagonists in clinical applications (Wei et al., 2005 ). DR5 was described more contributing than DR4 in the overall apoptotic activity of TRAIL during apoptosis (Kelley et al., 2005; Almasan and Ashkenazi, 2003; Ichikawa et al., 2001; Peto et al., 2000). One of the best antagonists of this protein is 
specific antibodies produced against the receptors which can attach to its antigen, the death receptor, and initiate the intrinsic pathway of apoptosis. In order to produce antibody, mammalian animals are susceptable candidates. The whole aim of this project was to induce apoptosis in cancerous cells by the aim of antibodies which were produced against death receptors. According to this, firstly three small parts of extracellular domain of DR5 receptor were produced and then injected to mice. Finally, the antibody elevation were evaluated in body.

\section{Material and Methods}

Peptide synthesis: Three small part of extracellular domain of the DR5 protein that contains 15 (CDSGEVELSPCTTTR), 21 (SCKYGQDYSTHWNDLLFCLRC) and 27 (NTVCQCEEGTFREEDSPEMCRKCRTGC) amino acids are produced in peptide synthesis center of National Institute of Genetic Engineering \& Biotechnology, Iran.

Liposom production: In order to produce liposome, egg phosphatidylcholine and cholesterol $(10: 1 \mathrm{w} / \mathrm{w})$ were dissolved in $50 \mathrm{ml}$ ethanol. The mixture shaked on stirre for 5 hours, until homogenized suspension obtained. Then ethanol content was evaporated and the gelose that attach to the round-bottom was resolved in $20 \mathrm{ml}$ sterile PBS. The resulting suspension was sonicated in 600 hearts for 5 minutes, then there was added $5 \mathrm{mg}$ dextran and the resulted mixture allocated in $2 \mathrm{ml}$ microtubes, and were restored in $-200 \mathrm{C}$. The efficiency and sizing of the produced liposomes were analysed by ZetasizerNano.

Immunization: Immunization of mice (Balb-C, 10 for each group) was performed in two groups for each peptide, in Pastour institute (Tehran, Iran) animal house. First group was immunized with $350 \mu$ g peptide combined with Fround `s adjuvant and second group were injected liposomes that contain total $350 \mu \mathrm{g}$ of each peptide per animal by intradermal and intrarectal injection in multiple sites, followed by three subsequent boosters.

Serum collection:In this section blood were collected and incubated in $37 \mathrm{oC}$ for 1 hour and then they were kept in $4 \mathrm{oC}$ overnight. After 24 hours, they were collected by centrifugation at $1000 \mathrm{rpm} 3 \mathrm{~min}$. The samples were stored in -200C until they were applied for ELISA assay.

ELISA assay: $20 \mu \mathrm{g}$ of DR5 protein (produced in Pastour, Pilot labrotoary) as an antigen were stuck onto a plastic surface of 96-well plates and incubated overnight at $40 \mathrm{C}$. After removing the supernatant, $200 \mu \mathrm{l}$ of BSA which was dissolved in PBST (PBS+ 05\% Tween-20) as a blocking buffer was added and after 1 hour incubation in $370 \mathrm{C}$, the sulotion were discard. The serial dilution (dilutions 1:1,000 to 1:64,000) of obtained antibodies (100 $\mu l$ per well) were added and incubated for 30 minutes. Supernatant were discarded and incubated the sandewich with secondry antibody (anti-IgG) HRP-conjugated $(100 \mu \mathrm{l})$. After 30 minutes and removing the solution, the reaction was detected by the marker changing colour TMB buffer and the rectionwas stoped with 1\% HCL. The absorbance was read in $450 \mathrm{~nm}$ with ELISA reader. In each step the wells were washed with $200 \mu$ PBST three times.

MTT Assay: The MTT method of cell determination was done in three days. First 10,000 MCF7 cells (human breast cancer cells)were cultured per well in the first day and they were incubated for 24 hours. In the second day, the media were removed carefully and the cells were treated by antibodies (final volume should be $200 \mu \mathrm{l}$ ). In the last day, the supernatant were removed and then added $100 \mu \mathrm{l}$ of $5 \mathrm{mg} / \mathrm{ml}$ MTT solution to each well. The cells were incubated for 2 hours at 370C, 5\% CO2 in culture incubator. The media were carfully removed and the color were resolved in MTT solvent (isopropanol). The absorbance of the color were read at $590 \mathrm{~nm}$. Then, the provided data were calculated with Pharms software.

Statistics. All data is expressed as mean \pm S.D. Di-erences between experimental and control groups were determined by using the T- test. Values of $\mathrm{P}<0.05$ were considered significant.

\section{Results}

The liposome produced was in the nano scale range

Liposoms size were measured with Zetasizer Nano $\mathrm{ZS}$ at $25^{\circ} \mathrm{C}$ (Figure 1). Sizing measurements were made on the neat liposome samples, where the samples were diluted with PBS almost $0.5 \mathrm{~nm}(\mathrm{OD})$. Liposoms without any cargo had $73.55 \mathrm{~nm}$ diameter but after loading peptide in each liposom production reaction, it grows til $360.9 \mathrm{~nm}$. Therefore, such differentionation in size scales demonstrates the loading of peptide in liposomes.

Obtained antibodies from two kind of injection were definitely recognize their antigens.

After the immunization of mice and blood sampling, the serum were separated. ELISA results demonstrated that not only antibody was produced but also they can
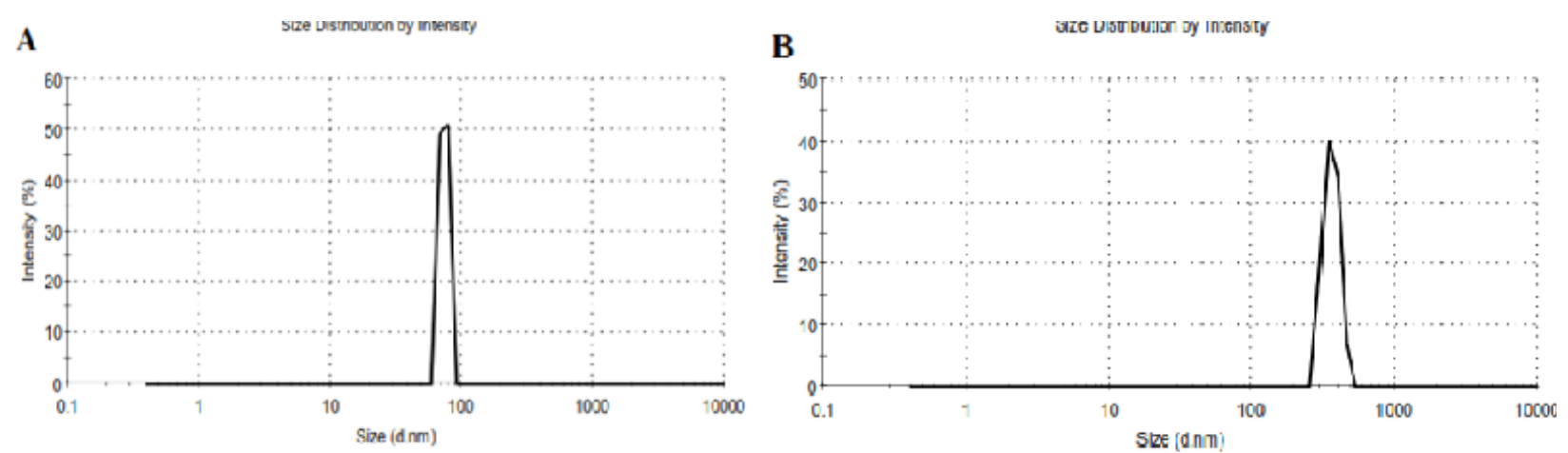

Figure 1. A Histogram of Liposom Size Distribution Determined by DLS; The Diameter Shown is the HydrodyNamic Dimeter of the Free Liposome (A) and Liposomes Loaded With Peptides (B) 
A

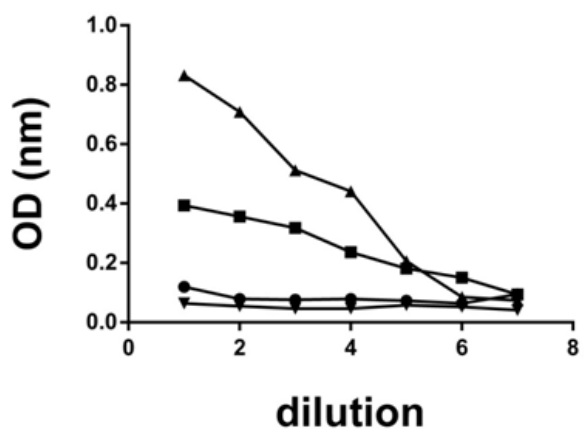

B

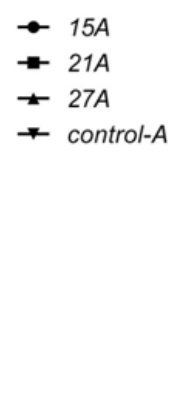

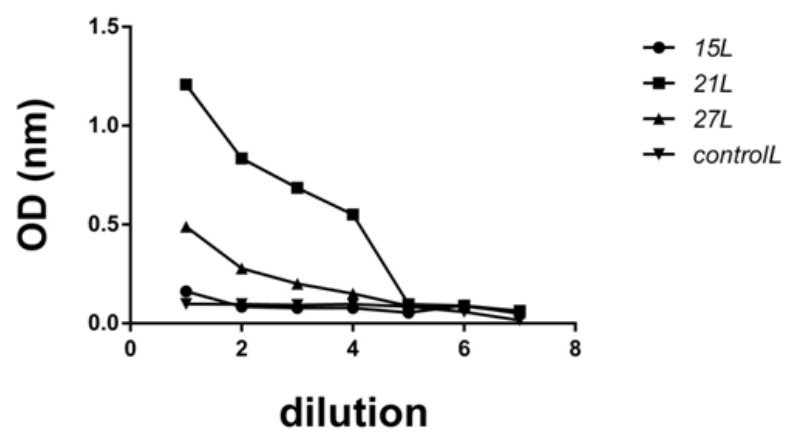

Figure 2. ELISA Results of IgG that Produced Against Peptides with 15, 21 and 27 Amino Acids from Extra Cellular Domain of the DR5 Protein; A, ELISA Result of Three Kinds of Antibodies Produced with Peptides Plus Fround's Adjuvant (15A, 21A and 27A) and Fround's Adjuvant without Peptide (ControlA); B, The Antibodies that Obtained from Mice with Immunization with the Same Peptides that Encapsulate in Liposome (15L, 21L and 27L) and Just Liposom (ControlL)

specifically attached to the peptides (Figure 2A). However, from three kind of peptides that were injected, antibody titers in the mice with two bigger peptides injection $(21$ and $27 \mathrm{AA})$, shows better results $(\mathrm{p}<0.05)$. But in the third one (15 AA), significant immune response induction was unmarkable, so the antibody volume is not obvious.

In the second group with liposomal peptide injection (figure 2B), besides the remarkable production of antibody in every three kind of immunized mice, each antibody interaction with their peptides in ELISA assay showed same manner with first group. The antibody was produced against 21 AA peptide $(21 \mathrm{~L})$ in this kind of injection, as same as the one was produced with Fround's adjuvant, and indicately they have showed the best result among all kinds.

Antibodies speciallyinduce death in breastcancer cell (MCF7 cell line).

According to the MTT assay results (demonstrated in figure 3), all kinds of antibodies except control ones (control A and control), could efficiently cause death in MCF7 cells (breast cancer cell line) ( $\mathrm{p}<$

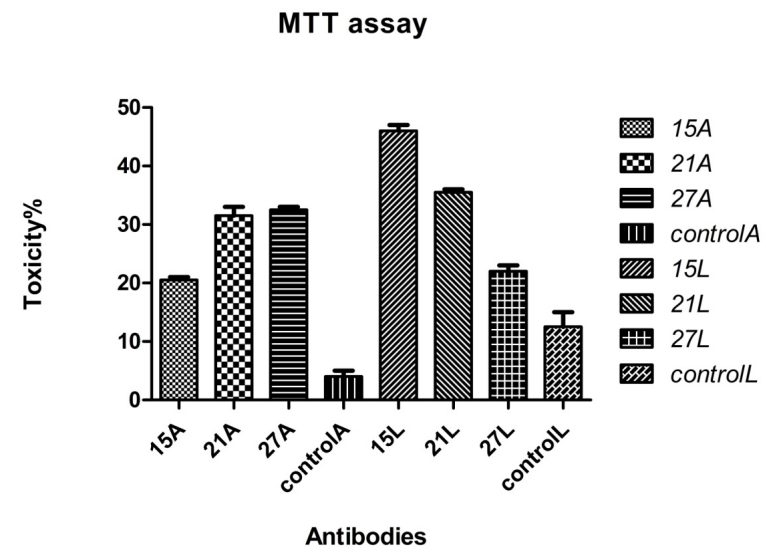

Figure 3. MTT Assay Results. The Resulted Toxicity Percent of IgGs (15A, 21 A, 27A, 15L, 21L, 27L and Controls) on MCF7 Cells. The Means Differences for $\mathrm{P}<0.05$ has Sense; The Percentage of Toxicity was Calculated Using the Following Formula, \%Toxicity $=($ AT/AUT -1$) \times 100$, where AT is Absorbance of Treated Cells, and AUT is Absorbance of Untreated Cells
0.05). In the first group with Fround's adjuvant and equivalent concentration of antibody, the largest peptide`s antibodies (27A) showed better effects remarkably. Indeed, the death effect of antibodies from smallest through largest peptide`s antibody increases respectively. But, in the second group, not only the smallest one's antibody had the most efficiency, but also as the peptides size growth, antibodie`s effect decreases.

\section{Discussion}

The induction of death in the cell without control, like cancerous cells can be helpful in deleting them. Among two main death pathways (necrosis and apoptosis) in mammalian cells, it seems apoptosis is the main pathway. Specially the dead receptors which are induced through dead receptors could be a good candidate.

Over the last thirty years, breast cancer trearment has gradually obtain many succeful event, such as early detection effectiveness and improvmens. In contrast, researchs have led to a significant decrease in breast cancer therapy in loco-reginals and systemic therapy (Gajewskim, 2007) Therefore, in order to increase the effectiveness of systemic treatment, targeted therapy have been exclusively investigated over the past two decades. Nowadays, it is demonstrated that one of the most promising therapeutic agents and targetable molecules are dead receptors and their ligand and agonists of course. Activating the TRAIL pathway with an alternative approach and the use of specific agonist antibodies (Ichikawa et al., 2001) is intersting. In such kinds of activation, they use the ligand receptor specificity and after attachment, biomimic and prolonged real ligand mechanism inducing in cells takes place. Monoclonal antibodies, as a one of such agonists, like, rituximab, terastuzamab and beracizumabare now widely applied in clinic and research based works for cancer therapy (Mori et al., 2004). Beyond DR4, DR5 is the predominant TRAIL receptor, which is expressed at the cell surface and mediates apoptotoc signals in human`s cancerous cells (Amirijavid and Hashemi, 2015 and Amirijavid and Hashemi, 2014).

However, IgG obtained from immunized mice against DR5 as it demonstrated, could specially induce dead. 
According to the peptide small size, we supposed that the diversity of the varied domains of antibody were restricted. It means although the scale of IgGs was obtained (polyclonal antibody) their variety to identify the antigens limitation. So, it can help to reduce the unspecific answers in body. Using two kind of adjuvants help us to obtain more antibody. According the small size of injected peptides, the kind of induction in mice immune response was important. Fraund's adjuvant as a convinient and useful adjuvant for immunization with protein, was the first choice. Though, liposomal peptoides was interesting too. Liposome as a carrier was expected to protect active compounds against chemical and enzymaticl attacks in the body. In other word, they were easily produced in large scale and provide longer drug half lives as well as tailored drug-release profile, reducing high peak plasma concentrations (Amirijavid and Hashemi., 2015; Amirijavid and Hashemi, 2014; Allon et al., 2012). Moreover, liposomes which loaded with our peptides, play an important role. They carry large amount of peptide safely to the body and deliver their cargo to the cytoplasm through conjugation with cellular membrane. Indeed, they not only do transport the peptide protectively in intrecellular spaces, but also deliver large amount of simultaneously in the intracellular space. Furthermore, it can increase cell uptake and subsequently, influences antibody production growth. The results emphasize the efficiency of using such kind of immunization in contrast to using Fraund's adjuvant.

In addition, in the same concentration of antibody (each from two kinds), we have different interaction manners. Antibody produced against the 15 aminoacids peptide in a liposomal form (15L) had the best answer among all antibodies. This is in contrast to its counterpart in injection with Fraund's adjuvant (15A). According to the petide scale, by decreasing the peptides size, the possibility of uptake and introduce of peptides to cell surface and at least producing antibody was declined by APC cells obviously. But, liposome protects peptide against degredation and increase delivery of enough amount to APC cells. On the other hand, the small size of the antigen can specify the antibody recognition site and this lead to increase in the subsequent response. However, in 21 aminoacids peptides in liposomal compound $(21 \mathrm{~L})$ the same correlation can be seen also. Therefore, cells uptake peptides easier with more possibility, by growing peptide size. So, in the first kind of injection, not only does mouse have the most amount of antibody production, but also the produced antibodies obtain the first killing step.

As a final conclusion, it is interesting to note that liposomal formol could be used as an adjuvant in immunization with small peptides. They carry, protect and deliver peptides as efficient as possible. In addition, the small peptides not only can induce immune system but also the produced antibodies can play a remarkable anti-cancer role.

\section{Acknowledgment}

Tehran Medical Sciences Branch, Islamic Azad University has provided the study with financial support.
No other financial disclosures are declared. All authors participated in organization of the manuscript.

\section{References}

Almasan A, Ashkenazi A (2003). Apo2L/TRAIL: apoptosis signaling, biology, and potential for cancer therapy. Cytokine Growth Factor Rev, 14, 337-48.

Amirijavid S, Hashemi M (2015). Detection of anticancer and apoptotic effect of the produced IgYs against the three extracellular domain of human DR5 protein. Iran J Cancer Prev, 8,109-15.

Amirijavid S, Hashemi M (2014). Anticancer effect of the IgY that produced against a small peptide with 15 amino acids of human DR5 on MCF7 cell line. JPS, 5,1-6.

Ashkenazi A (2002). Targeting death and decoy receptors of the tumor necrosis factor superfamilly. Nat Rev Cancer, 2, 420-300.

Bellail AC, Qi L, Mulligan P, et al (2009). TRAIL agonists on clinical trials for cancer therapy: the promises and the challenges. Rev Recent Clin Trials , 4, 34-41.

Benedict CA, Banks TA, et al. (2003). Death and survivel: viral regulation of TNF signaling pathways.Curr Opin Immunol, 15, 59-65.

Bodmer JL, Schneider P, et al (2002). The molecular architecture of the TNF superfam.Trends. Biochem Sci, 27,19-26.

Cha SS, Sung BJ, et al. (2000). Crystal structure of TRAIL-DR5 complex identifies a critical role of the unique frame insertion in conferring recognition specificity. J BiolChem, 275, 31171-7.

Chaudhary PM, Eby M, et al (1997). Death receptor 5, a new member of the TNFR family, and DR4 induce FADD-dependent apoptosis and activate the NF-kappa B pathway. Immunity, 7,821-30.

Heidari MH, Porghasem M, Mirzaei N, et al (2014). The effect of high level natural ionizing radiation on expression of PSA, CA19-9 and CEA tumor markers in blood serum of inhabitants of Ramsar, Iran. J Environ Radioact, 128, 64-7.

Gajewski TF (2007). On the TRAIL toward death receptor-based cancer therapeutics. J Clin Oncol, 25,1305-7.

Ichikawa K, Liu W, et al (2001). Tumoricidal activity of a novel anti-human DR5 monoclonal antibody without hepatocyte cytotoxicity. Nat Med,7, 954-60.

Kelley RF, Totpal K, et al (2005). Receptor-selective mutants of apoptosis-inducing ligand 2/tumor necrosis factor-related apoptosis-inducing ligand reveal a greater contribution of death receptor (DR) 5 than DR4 to apoptosis signaling. $J$ BiolChem, 280, 2205-12.

Mahalingam D, Szegezdi E, et al (2009). TRAIL receptor signalling and modulation: Are we on the right TRAIL? Cancer Treat Rev, 35, 280-8.

Mori E, Thomas M, et al (2004). Human normal hepatocytes are susceptible to apoptosis signal mediated by both TRAIL-R1 and TRAIL-R2. Cell Death Differ, 11, 203-7.

Movafagh A, Hajifathali A, Zamani M (2011). Secondary chromosomal abnormalities of de novo acute myeloid leukemia-a first report from the Middle East. Asian Pac J Cancer Prev, 12, 2991-4.

Movafagh A, Mirfakhraei R, Mousavi-Jarrahi A (2011). Frequent incidence of double minute chromosomes in cancers, with special up-to-date reference to leukemia. Asian Pac J Cancer Prev, 12, 3453-6.

Movafagh A, Hajifathali A, Isfahani F, et al (2012). Geographic heterogeneity of cytogenetic characteristics of acute myeloid leukemia in the early detection. Iran J Cancer Prev, 2, 85-89.

Pan G, Ni J, et al (1997). Anantagonist decoyreceptor and a death domain-containing receptor for TRAIL. Science, 277,815-8. 
Pan G, O'Rourke K, et al (1997). The receptor for the cytotoxic ligand Trail. Science, 276,111-3.

Peto R, Boreham J, et al (2000). UK and USA breast cancer deaths down 25\% in year 2000 at ages 20-69 years. Lancet, 355, 1822-3.

Reed JC (2006). Drug insight cacner therapy strategis, based on restoration of endogenous cell death mechanism. Nat clin pract oncol, 3, 388-98.

Schneider P, Thome M, et al (1997). TRAIL receptors 1 (DR4) and 2 (DR5) signal FADD-dependent apoptosis and activate NF-kappaB. Immunity, 7, 831-6.

Seifi-Alan M, Shamsi R, Ghafouri-Fard S, et al (2014). Expression analysis of two cancer-testis genes, FBXO39 and TDRD4, in breast cancer tissues and cell lines. Asian Pac J Cancer Prev, 14, 6625-9.

Shargh SA, Sakizli M, Khalaj V, et al ( 2014) Downregulation of E-cadherin expression in breast cancer by promoter hypermethylation and its relation with progression and prognosis of tumor. Med Oncol, 31, 250-9.

Walczak H, Degli-Esposti MA, et al (1997). Trail R2: a novel apoptosis mediating receptor. $E M B O, 16,5386-97$.

Wei W, Liu Y, et al (2005). Current understanding on the immunological functions of tumor necrosis factor-related apoptosis-inducing ligand. Cell MolImmunol, 2, 265-9.

Wiley SR, Schooley K, et al (1995). Identification and characterization of a new member of theTNF family that induces apoptosis. Immunity, 3, 673-82.

Wu GS, Burns TF, et al (1997). KILLER/DR5 is a DNA damage-inducible p53-regulated death receptor gene. Nature Genet, 17, 141-3. 